\title{
Influence of microwave vacuum drying on the effective moisture diffusivity of seedless white grapes
}

\author{
Yongdong LEI ${ }^{1,2} \mathbb{D}$, Jiluan $\mathrm{CHEN}^{1}$, Zhenghong $\mathrm{ZHANG}^{2}$, Xiaorong DENG ${ }^{1 *}$
}

\begin{abstract}
In this study, the effects of microwave power, vacuum degree and load weight on the moisture content of seedless white grapes (Vitis vinifera L.) during microwave vacuum drying were investigated. The result found that during microwave vacuum drying, the effective moisture diffusivity $\left(D_{\text {eff }}\right)$ of seedless white grapes ranged between $1.0232 \times 10^{-9}$ and $4.6354 \times 10^{-9} \mathrm{~m}^{2} / \mathrm{s}$. The $D_{\text {eff }}$ values increased with the increase in the microwave power and the decrease in the load weight, the vacuum degree played a relatively minor role. The kinetics of moisture ratio and drying time were established, with the drying process following the Page model, as reflected by the fitting between model-predicted and measured data. The Page model was demonstrated to precisely describe and predict the moisture content variation in seedless white grapes during microwave vacuum drying.
\end{abstract}

Keywords: seedless white grapes; microwave vacuum drying; effective moisture diffusivity; kinetic model.

Practical Application: The moisture content monitoring in seedless white grapes during microwave vacuum drying.

\section{Introduction}

Seedless white grapes (Vitis vinifera L.) have been identified to be the most suitable variety of grapes for making raisins because of their characteristics such as full fruit size, special taste, rapid growth, ability to form large clusters, high sweetness, and seedlessness (Wang et al., 2017). Fresh seedless white grapes can be made into raisins via direct sun drying, sheltered drying, or hot air drying (Khiari et al., 2019). However, inappropriate drying methods can lead to nutrition loss and microbial proliferation, ultimately lowering the raisin quality (Olivati et al., 2019) Hence, emerging novel food processing methods have aroused the attention of researchers. The methods involve incorporating techniques such as pressure, ultrasound, vacuum, microwave (Peña-Gonzalez et al., 2019; Shabbir et al., 2019), freeze and microwave (Li et al., 2020), high humidity and hot air (Bai et al., 2013), pulsed electric field (Nowacka et al., 2019), vibrating fluid (Meili et al., 2020), convective and microwave (Izli \& Polat, 2019), and radio frequency-vacuum (Zhou et al., 2018) into the drying process. These novel drying techniques are designed to achieve cost-effectiveness, operational simplicity, and energy efficiency.

Microwave vacuum drying combines microwave and vacuum drying techniques and has advantages such as high drying rate, use of low temperature, high efficiency, and operational safety. While microwave provides a uniform heat source for vacuum drying, reducing the overheating of parts that do not require heating, the vacuum environment allows foodstuff to be dried under a relatively low temperature, which facilitates the preservation of their color, fragrance, flavor, and bioactive substances (Ozcan-Sinir et al., 2019; Curi et al., 2019). So far, microwave vacuum drying has been recognized as the most promising method for the preservation of fruits and vegetables.
The effectiveness of the method in the drying of lotus and agaricus bisporus and carrots has already been verified by several studies (Cao et al., 2019; Jiang et al., 2020; Zhao et al., 2020). Yang et al. (2019) demonstrated that microwave vacuum drying enhanced the quality of 3D-printed mango juice jelly. Microwave vacuum drying has, thus, been confirmed to be an effective method in enhancing the quality of 3D-printed food. The study of Rodriguez et al. (2019) showed that microwave drying also allowed a good surface color in the final product of raspberries (Rubus Idaeus). The method, therefore, is highly suitable for used in large-scale industrial practice because of its short drying period and the ability to preserve the nutritive value of foodstuff.

During drying, moisture loss occurs due to liquid or vapor diffusion. Fick's laws of diffusion define the relationship between diffusivity and drying rate based on the mechanism of drying (Ouaabou et al., 2020). A series of solutions is the most commonly used format to describe a drying process, which depends on the initial and boundary conditions, and the material shape. Effective moisture diffusivity $\left(D_{\text {eff }}\right)$ is a critical parameter in the modeling, design, and optimization of the drying process. $D_{\text {eff }}$ describes the possible mechanisms of movement of water molecules within foodstuff (Dutta et al., 2020; Ozcan-Sinir et al., 2019; Song et al., 2020; Zielinska et al., 2019). The mechanisms include liquid diffusion, vapor diffusion, surface diffusion, capillary flow, hydrodynamic flow, and osmotic dehydration. However, the exact mechanism remains to be confirmed.

In recent years, several researchers have studied the relationship between $D_{\text {eff }}$ and the geometrical shape, moisture content, and temperature of agricultural products such as potatoes 
(McMinn et al., 2003), garlic (Sharma \& Prasad, 2004), and red peppers (Horuz et al., 2020). The internal heating mechanism of the foodstuff and the conditions of microwave vacuum drying are different from the heating mechanism and conditions of regular drying. However, no study has reported the moisture diffusion characteristics of seedless white grapes during microwave vacuum drying. Hence, this study aimed to confirm the effective moisture diffusivity of fresh seedless white grapes dried using microwave vacuum drying. The dependence of $D_{\text {eff }}$ on microwave power, degree of vacuum, and load weight was also investigated, given the fact that they could all influence the drying rate. Results of this study are expected to shed light on the microwave vacuum drying mechanism of seedless white grapes and aid the development of novel dried seedless white grape products.

\section{Materials and methods}

\subsection{Materials}

Fresh "Thompson" seedless white grapes were purchased from the local market in Shihezi, Xinjiang, China. Grapes with uniform weight, that is, a single fruit weight of $3.00 \pm 0.55 \mathrm{~g}$ and a single cluster weight of $350 \pm 10.55 \mathrm{~g}$, were picked up for the study. They were then flushed thoroughly using clean water. The grape stems, other impurities, and the damaged or rotten grapes were removed subsequently. Hot air drying (Khamtree et al., 2019) was used to measure the initial moisture content of the fresh seedless white grapes, which was observed to be between 78.78 and $81.23 \%$.

\subsection{Microwave vacuum drying}

Fresh seedless white grapes were dried under microwave vacuum using a RWBZ-24S microwave vacuum dryer (Surui, Nanjing, China). The microwave power, degree of vacuum, and load weight were 50 to $300 \mathrm{~W},-0.02$ to $-0.06 \mathrm{MPa}$, and 200 to $1000 \mathrm{~g}$, respectively.

The grape samples were spread uniformly on the loading surface of the vacuum dryer as a single layer. When the required vacuum degree was achieved, appropriate microwave power was applied. The microwave oven was closed and vacuum released every $10 \mathrm{~min}$ to record the sample weight. It took about 30-60 $s$ to complete a single measurement. Drying was stopped when the moisture content reached to $13.0 \pm 0.5 \%$.

\subsection{Effective moisture diffusivity}

The effective moisture diffusion rate was calculated based the method proposed by Dak \& Pareek (2014) and Abhishek Dutta et al. (2020), with minor modifications as Equation (1) and Equation (2):

Dry basis moisture content $(\mathrm{g} / 100 \mathrm{~g})=\frac{m_{t-} m_{g}}{m_{g}} \times 100$

Moisture water loss rate $(\mathrm{g} / \mathrm{min})=\frac{\Delta m}{\Delta t}$ where $m_{\mathrm{t}}$ is the material weight (g) at time $t ; m_{\mathrm{g}}$ is the material weight ( $\mathrm{g}$ ) when it is thoroughly dried; $\Delta m$ is the mass difference ( $\mathrm{g}$ ) between two adjacent measurement points; and $\Delta t$ is the time difference ( $\mathrm{min}$ ) between two adjacent measurement points.

$M R=\frac{M_{t}-M_{e}}{M_{o}-M_{e}}$

where $M R$ is the moisture ratio; $M_{t}$ is the dry basis moisture content $(\mathrm{g} / 100 \mathrm{~g})$ at time $t ; M_{0}$ is the initial dry basis moisture content ( $\mathrm{g} / 100 \mathrm{~g})$; and $M_{\mathrm{e}}$ is the dry basis moisture content $(\mathrm{g} / 100 \mathrm{~g})$ when the process is at equilibrium.

When the drying process reaches equilibrium, $M_{\mathrm{e}}$ becomes much smaller than $M_{0}$ and $M_{\mathrm{t}}$; hence, Equation 3 can be simplified as Equation 4.

$M R=\frac{M_{t}}{M_{o}}$

The effective moisture diffusivity $\left(\mathrm{m}^{2} / \mathrm{s}\right), D_{\text {eff }}$ can be calculated using the following equation:

$\ln M R=\ln \frac{8}{\pi^{2}}-\frac{\pi^{2} D_{e f f}}{r^{2}} t$

where $r$ is the diameter $(\mathrm{mm})$ of a seedless white grape and $t$ is the drying time (s).

\subsection{Statistical analysis}

Each measurement was repeated three times, and results are presented as mean \pm standard deviation (SD). The SPSS Statistics Version 17.0 (International Business Machines Corporation, Chicago, IL, USA) was used to evaluate the significance of difference $(\mathrm{P}<0.05)$ among the data. All figures in this study were plotted using Origin 8.0 (OriginLab Corp., Northampton, NC, USA).

\section{Results and discussion}

\subsection{Microwave vacuum drying characteristics of seedless white grapes}

The influence of microwave power on the drying efficiency of seedless white grapes during the microwave vacuum drying, the drying curve, and moisture loss curve are all presented in Figure $1 \mathrm{~A}$ and $\mathrm{B}$. The dry basis moisture content of the seedless white grapes is seen to decrease exponentially (Figure 1A). The dry basis moisture content is also found to decrease more rapidly with the increase in the microwave power. Hence, under the same vacuum degree and load weight, a shorter drying time is required with the increase in the microwave power. The drying of seedless white grapes under varying values of microwave power consists of the acceleration and deceleration stages (Figure 1B). The rate of moisture loss from the seedless white grapes increased with the increase in the microwave power. The time required for 

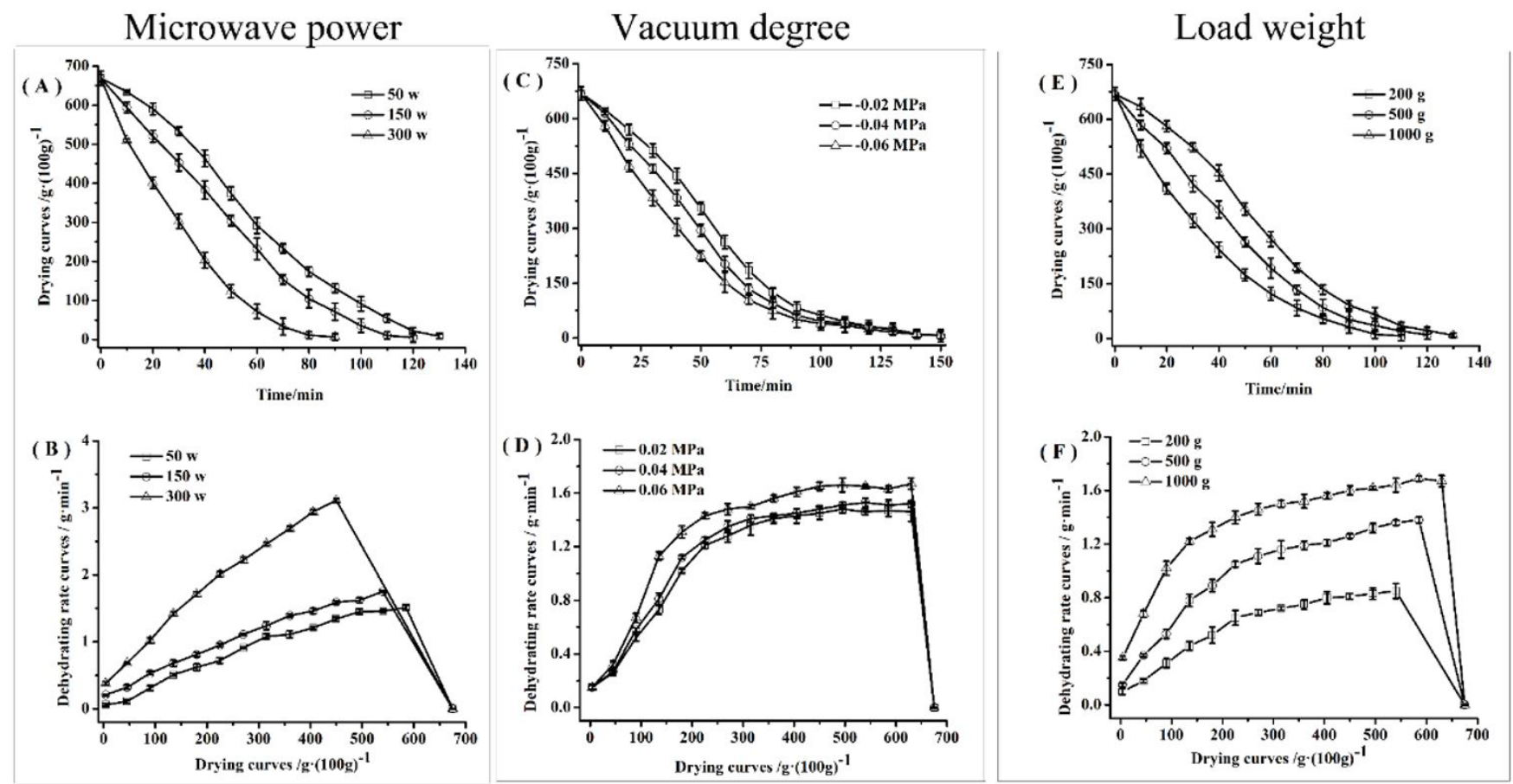

Figure 1. The drying curves $(A, C$ and $D)$ and moisture loss rate curves $(B, D$ and $F)$ of seedless white grapes under different microwave drying parameters.

moisture loss during this acceleration stage decreased and the moisture loss curve became steeper. Meanwhile, the intensity of microwave radiation was found to have a profound influence on the drying rate of the seedless white grapes. Even when the rate of moisture loss was constant, the rate of drying was found to increase with the increase in the intensity of the microwave radiation. Consistent with the microwave drying rates of red peppers obtained by Horuz et al. (2020), it was observed that the drying time decreased with the increase in the microwave power, which may be attributed to the fact that a higher intensity of microwave radiation facilitated energy accumulation within the material. The high energy accumulation further increased the vapor pressure difference between the interior and surface of the material, which made it easier for water molecules to reach their boiling point. Results obtained by Dev et al. (2008) indicated that microwave treatment dramatically enhanced the drying rate of grapes as compared to the pulsed electric field and regular chemical pretreatment methods.

The influence of the vacuum degree on the drying rate of seedless white grapes is shown in Figure 1C and D. Under fixed microwave power and load weight, the dry basis moisture content of the seedless white grapes is seen to decrease with the increase in the vacuum degree (Figure 1C). While the microwave vacuum drying of seedless white grapes mainly consists of the acceleration and deceleration stages, the constant-rate period is relatively short (Figure 1D). The whole process was consistent with the drying rate variation mechanism proposed traditionally. In addition, even when the rate of moisture loss was constant, a higher vacuum degree was found to lead to a higher drying rate of seedless white grapes. The phenomenon was due to the fact that the higher vacuum degree accelerated the evaporation of water (Balzarini et al., 2018). When the vacuum degree was relatively low, the boiling point of water became relatively high. The local temperature of the interior of the material increased dramatically, which burned the material, hindering the diffusion of water. The results were consistent with the results of the microwave drying of lotus seeds obtained by Zhao et al. (2017) However, accelerating the process of evaporation by increasing the vacuum degree was the major limitation. Considering other factors such as energy efficiency and the overall product quality, the optimum vacuum degree for microwave vacuum drying was observed to be around $-0.04 \mathrm{MPa}$.

The influence of the load weight on the drying rate of seedless white grapes is shown in Figure 1E and F. Under fixed vacuum degree and microwave power, rate of decrease of the dry basis moisture content with the increase in the load weight is observed to be slow, resulting in a longer drying time (Figure 1E). The phenomenon may be attributed to the fact that since the amount of water to be removed increased with the increase in the load weight at fixed microwave power (Zhao et al., 2017), the microwave energy absorbed by the seedless white grapes per unit weight decreased. The microwave vacuum drying of seedless white grapes under varying load weight still mainly consists of the acceleration and deceleration stages, with the rate of water loss increasing with the increase in the load weight (Figure 1F).

The microwave vacuum drying characteristics of seedless white grapes indicated that factors such as high microwave power, low degree of vacuum, and low load weight facilitated moisture evaporation. The microwave vacuum drying of seedless white grapes mainly occurred during the deceleration stage, which was consistent with the results of the studies conducted on apple pomace (Wang et al., 2007), mushroom (Giri \& Prasad, 2007), garlic (Sharma \& Prasad, 2001), and 
carrot (Sutar \& Prasad, 2007). Meanwhile, different from cut fruits, the skin of the seedless white grapes can hinder water transfer during drying (Clary et al., 2005). When compared with the process using single fixed microwave power, the one using incremental power was found to enhance the characteristics of dried grapes. Therefore, during drying, it is advisable to reduce the microwave power in phases to prevent overheating.

\subsection{Influence of microwave vacuum drying on the effective moisture diffusivity of seedless white grapes}

The moisture diffusion characteristics in the inner system of food materials, including molecular diffusion, vapor diffusion, liquid mechanical flow, and other transport mechanisms, can be represented using the effective moisture diffusivity $\left(D_{\text {eff }}\right)$. The variation in $D_{\text {eff }}$ is a complicated system function (Eminoglu et al., 2019; Karathanos et al., 1990). The drying rate declining cycle was analyzed by measuring the effective moisture diffusivity $\left(D_{\text {eff }}\right)$, and the influence of the processing parameters and moisture content on the drying kinetics.

The drying of seedless white grapes was mainly in the deceleration stage, and the effective moisture diffusivity was calculated using Fick's second law of diffusion. As shown in Equation 5, a linear relationship was observed between $\ln M R$ and drying time $t$ for seedless white grapes during the drying process. Figure 2 shows the change in $\ln M R$ with respect to $t$. The $D_{\text {eff }}$ values of the seedless white grapes were obtained using linear regression under different microwave vacuum drying conditions (Table 1).

As can be seen in Table 1, with the other conditions fixed, the $D_{\text {eff }}$ value at $-0.02 \mathrm{MPa}$ was comparable to that at $-0.04 \mathrm{MPa}$. When the load weight was between 200 and $1000 \mathrm{~g}$, the $D_{\text {eff }}$ value was between $1.0232 \times 10^{-9}$ and $4.6354 \times 10^{-9} \mathrm{~m}^{2} / \mathrm{s}$. As the load weight decreased and the microwave power increased, $D_{\text {eff }}$ increased as well. This observation was similar to the results calculated using Fick's law of diffusion by Cuevas et al. (2019) who found that the $D_{\text {eff }}$ values during the drying process decreased with an increase in the sample thickness. The influence of load weight and microwave power on the $D_{\text {eff }}$ values was more substantial than that of vacuum degree, among which the influence of

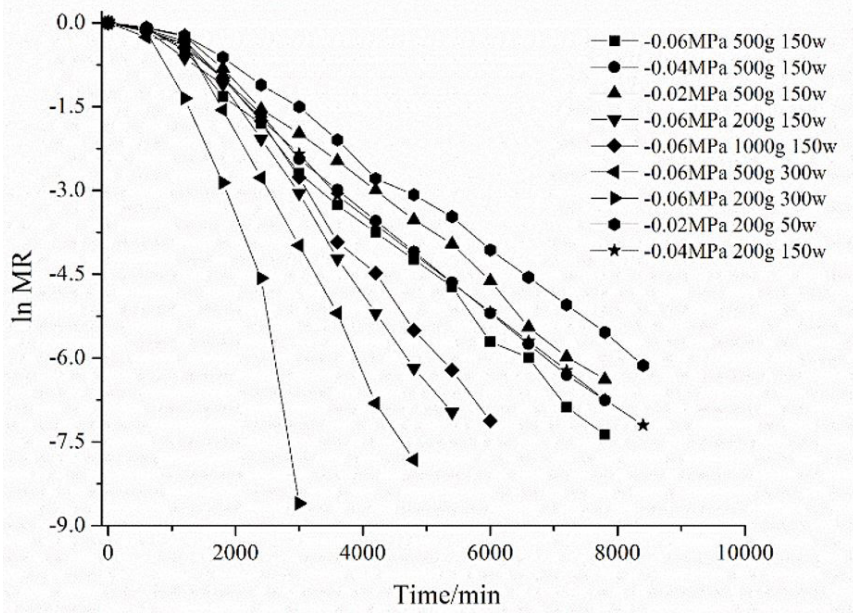

Figure 2. The lnMR change with respect to $t$ of seedless white grapes. microwave power was found to be the most profound. Meanwhile, the conclusion obtained from drying pomegranate arils that $D_{\text {eff }}$ increased with the increase in the processing strength was validated (Briki et al., 2019). It was then concluded that with the increase in the microwave power and the decrease in the load weight, the drying time decreased but the effective moisture diffusivity increased dramatically. The results were similar to the microwave vacuum drying results of edamame (Islam et al., 2019) and potato chips (Azimi-Nejadian \& Hoseini, 2019).

Under all microwave vacuum drying conditions, the effective moisture diffusivity $\left(D_{\text {eff }}\right)$ increased with the decrease in the moisture content, as shown in Figures 1. The results indicate that the vapor permeability increased with the decrease in the moisture content when the pores were open. During the initial drying stage, the moisture content was relatively high so the absorbed microwave energy was high. The high microwave energy increased the water vapor pressure within the vapor bubbles and caused the bubble pressure. During the initial drying stage, liquid diffusion was the major moisture transfer mechanism. As the drying proceeded, the moisture vapor diffusion would become the major mechanism during the late stage. İlter et al. (2018) proposed a mathematical model to describe the microwave drying process of a porous medium, with microwave power as one of the key drying parameters. From this model, it may be inferred that moisture evaporation starts once the absorbed microwave energy reaches the local porous pressure.

\subsection{Establishment and testing of the kinetics of the microwave vacuum drying of seedless white grapes}

Drying is a complex process in which both heat and mass transfers occur simultaneously. The drying of fruits and vegetables is especially complicated due to their substantial structural variations (Erbay \& Icier, 2010). In real practice, the microwave vacuum dryer used in microwave vacuum drying is much more complicated than the device used to remove only moisture. Hence, effective models are necessary in process design, optimization, energy integration, and control. The three most commonly used drying models (Eminoglu et al., 2019; Ozcan-Sinir et al., 2019) in fruits and vegetables are the following:

Exponential model: $M R=\exp (-k t)$

One-way diffusion model: $M R=A \exp (-B t)$

Page model: $M R=\exp \left(-k t^{n}\right)$

where $k, A, B$, and $n$ are the model parameters.

It may be inferred from Equations 6, 7, and 8 that the exponential model is a special form of the one-way diffusion and Page models, both of which could be used to simulate the microwave vacuum drying of seedless white grapes. A logarithm fetch on Equations 7 and 8 led to

$\ln M R=-B t+\ln A$ 
$\ln (-\ln M R)=\ln k+n \ln t$

The $\ln M R$ vs. $t$ curve (Figure 3$)$ and the $\ln (-\ln M R) v s . \ln t$ curve (Figure 4) of seedless white grapes dried under different microwave vacuum drying conditions were plotted based on the experimental data.

As shown in Figures 3 and 4, the $\ln (-\ln M R)$ vs. $\ln t$ relationship was more linear than the $\ln M R$ vs. t relationship, which indicates that the kinetics of the microwave vacuum drying of seedless white grapes follows the Page model. The linear regression results of Equation 10 are presented in Table 2.

Regression factors, SE (standard deviation), $t$ value, and $\mathrm{R}^{-2}$, were used to evaluate the goodness-of-fit for all the drying models. It may be inferred from Table 2 that the drying parameters in the model, that is, $k$ and $n$, were relevant functions of vacuum degree, load weight, and microwave power. A linear polynomial regression was used to obtain the above parameters:

$k=x_{0}+x_{1} V+x_{2} L+x_{3} P$

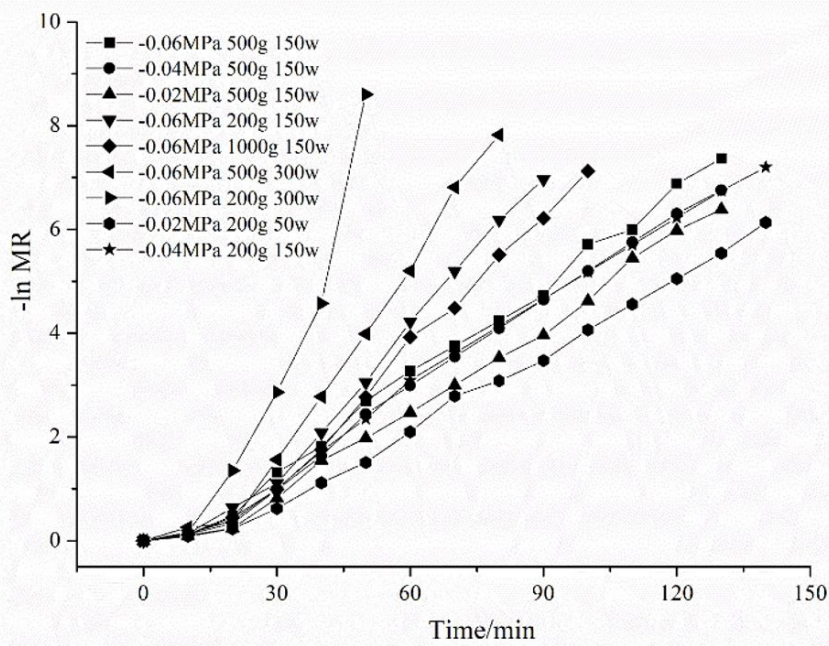

Figure 3. The -lnMR change with respect to $t$ of seedless white grapes under varying microwave vacuum drying conditions. $n=y_{0}+y_{1} V+y_{2} L+y_{3} P$

where $V$ is the vacuum degree (MPa); $L$ is the load weight $(\mathrm{g})$; $P$ is the microwave power (w); and $x_{0}, x_{1}, x_{3}, y_{0}, y_{1}, y_{2}, y_{3}$ are underdetermined coefficients.

Using the $k$ and $n$ values obtained under different vacuum degrees, load weight, and microwave power, we solved Equations 11 and 12 and obtained the following: $\mathrm{x}_{0}=0.0121675$, $\mathrm{x}_{1}=-0.0001478, \mathrm{x}_{2}=-0.00001235, \mathrm{x}_{3}=0.000098 ; \mathrm{y}_{0}=0.5634862$, $\mathrm{y}_{1}=0.00015863, \mathrm{y}_{2}=0.0004431, \mathrm{y}_{3}=0.0001235$. The drying kinetic model is as follows:

$$
M R=\exp \left(-k t^{n}\right)
$$

$$
k=0.0121675-0.0001478 V-0.0000512 L+0.000098 P
$$$$
\mathrm{n}=0.5634862+0.00015863 V+0.0004431 L+0.0001235 P
$$

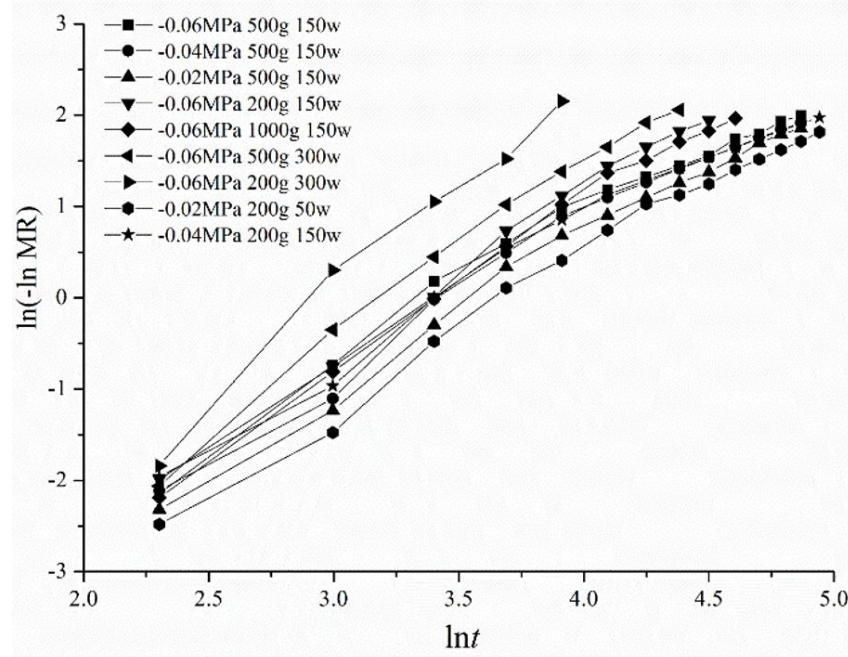

Figure 4. The $\ln (-\ln M R)$ change with respect to $\ln$ of seedless white grapes under varying microwave vacuum drying conditions.

Table 1. Effective moisture diffusivity of seedless white grapes under microwave vacuum drying.

\begin{tabular}{cccccc}
\hline Vacuum degree $(\mathrm{MPa})$ & Load weight $(\mathrm{g})$ & Microwave power $(\mathrm{W})$ & Linear regression equation & $R^{2}$ & $D_{\text {eff }} \times 10^{-9}\left(\mathrm{~m}^{2} \cdot \mathrm{s}^{-1}\right)$ \\
\hline-0.06 & $501.54 \pm 2.34$ & 150 & $\ln M R=-0.00099 t+0.40736$ & 0.99390 & $1.6538 \pm 0.2498^{\mathrm{e}}$ \\
-0.04 & $502.45 \pm 3.21$ & 150 & $\ln M R=-0.00093 t+0.43893$ & 0.99336 & $1.2753 \pm 0.2231^{\mathrm{f}}$ \\
-0.02 & $501.78 \pm 2.56$ & 150 & $\ln M R=-0.00087 t+0.54352$ & 0.98878 & $1.2065 \pm 0.1746^{\mathrm{f}}$ \\
-0.06 & $202.15 \pm 3.52$ & 150 & $\ln M R=-0.00014 t+0.80972$ & 0.97049 & $2.0675 \pm 0.2486^{\mathrm{c}}$ \\
-0.06 & $1004.23 \pm 3.83$ & 150 & $\ln M R=-0.00128 t+0.80571$ & 0.97537 & $1.8463 \pm 0.3218^{\mathrm{d}}$ \\
-0.06 & $502.86 \pm 3.57$ & 300 & $\ln M R=-0.00175 t+1.00933$ & 0.95683 & $3.5892 \pm 0.2142^{\mathrm{b}}$ \\
-0.06 & $202.91 \pm 2.17$ & 300 & $\ln M R=-0.00275 t+1.20132$ & 0.86086 & $4.6354 \pm 0.3473^{\mathrm{a}}$ \\
-0.02 & $201.62 \pm 2.85$ & 50 & $\ln M R=-0.00077 t+0.54361$ & 0.98919 & $1.0232 \pm 0.1872^{\mathrm{g}}$ \\
-0.04 & $203.75 \pm 3.59$ & 150 & $\ln M R=-0.00092 t+0.37549$ & 0.99456 & $1.2237 \pm 0.1034^{\mathrm{f}}$ \\
\hline
\end{tabular}

Data are presented as means \pm standard deviation. ${ }^{a, b, c, d, e, f, g}$ Same letters in columns indicates that no statistically significant difference was observed between the samples. 
Table 2. Linear regression analyses.

\begin{tabular}{|c|c|c|c|c|c|c|c|c|}
\hline Vacuum degree $(\mathrm{MPa})$ & Load weight (g) & $\begin{array}{l}\text { Microwave } \\
\text { power (W) }\end{array}$ & Parameter & $\begin{array}{l}\text { Regression } \\
\text { coefficient }\end{array}$ & SE & $t$ & $R^{2}$ & $P$ \\
\hline \multirow{2}{*}{0.06} & \multirow{2}{*}{$502.34 \pm 2.76$} & \multirow{2}{*}{150} & $\ln k$ & -5.34062 & 0.31489 & -16.96054 & \multirow{2}{*}{0.97131} & \multirow{2}{*}{$<0.0001$} \\
\hline & & & $n$ & 1.54838 & 0.07673 & 20.17956 & & \\
\hline \multirow{2}{*}{0.04} & \multirow{2}{*}{$501.43 \pm 3.25$} & \multirow{2}{*}{150} & $\ln k$ & -5.57697 & 0.29832 & -18.69448 & \multirow{2}{*}{0.97528} & \multirow{2}{*}{$<0.0001$} \\
\hline & & & $n$ & 1.58338 & 0.07269 & 21.78140 & & \\
\hline \multirow{2}{*}{0.02} & \multirow{2}{*}{$503.62 \pm 2.46$} & \multirow{2}{*}{150} & $\ln k$ & -5.9475 & 0.23368 & -25.45188 & \multirow{2}{*}{0.98570} & \multirow{2}{*}{$<0.0001$} \\
\hline & & & $n$ & 1.63841 & 0.05694 & 28.77345 & & \\
\hline \multirow{2}{*}{0.06} & \multirow{2}{*}{$203.87 \pm 3.49$} & \multirow{2}{*}{150} & $\ln k$ & -6.22198 & 0.19125 & -32.53348 & \multirow{2}{*}{0.99406} & \multirow{2}{*}{$<0.0001$} \\
\hline & & & $n$ & 1.84837 & 0.05051 & 36.59278 & & \\
\hline \multirow{2}{*}{0.06} & \multirow{2}{*}{$1002.32 \pm 5.28$} & \multirow{2}{*}{150} & $\ln k$ & -6.26572 & 0.21643 & -28.95059 & \multirow{2}{*}{0.99164} & \multirow{2}{*}{$<0.0001$} \\
\hline & & & $n$ & 1.82504 & 0.05584 & 32.68386 & & \\
\hline \multirow{2}{*}{0.06} & \multirow{2}{*}{$503.36 \pm 2.53$} & \multirow{2}{*}{300} & $\ln k$ & -6.38353 & 0.30715 & -20.78305 & \multirow{2}{*}{0.98760} & \multirow{2}{*}{$<0.0001$} \\
\hline & & & $n$ & 1.96823 & 0.08330 & 23.62848 & & \\
\hline \multirow{2}{*}{0.06} & \multirow{2}{*}{$203.08 \pm 3.19$} & \multirow{2}{*}{300} & $\ln k$ & -7.20484 & 0.58403 & -12.33641 & \multirow{2}{*}{0.97881} & \multirow{2}{*}{$<0.0001$} \\
\hline & & & $n$ & 2.40532 & 0.17648 & 13.62911 & & \\
\hline 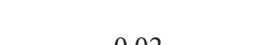 & $20177+41$ & 50 & $\ln k$ & -6.16107 & 0.22117 & -27.85719 & 67 & $=00001$ \\
\hline 0.02 & $201.6 / \pm 4.21$ & 50 & $n$ & 1.64614 & 0.05305 & 31.03155 & $0.9000 /$ & $<0.0001$ \\
\hline & 06 & 150 & $\ln k$ & -5.20022 & 0.26315 & -19.76130 & 726 & 01 \\
\hline 0.04 & $202.09 \pm 2.86$ & 150 & $n$ & 1.49316 & 0.06312 & 23.65677 & $0.97 / 26$ & $<0.0001$ \\
\hline
\end{tabular}

Note: $\mathrm{n}$ : the number of samples; SE: standard error; t: variable significance test; P: significant differences; $\mathrm{R}^{2}$ : degree of the equation fit.

The Page drying kinetic model of the Equation 13 was also tested. Under a vacuum degree of $-0.04 \mathrm{MPa}$, load weight of $500 \mathrm{~g}$, and a microwave power of $150 \mathrm{~W}$, the measured microwave vacuum drying data of seedless white grapes were compared with the Page model predicted data (Figure 5). As shown in Figure 5, the experimental data fits well with the model predicted data, which demonstrates that the Page model reflects the moisture rate variation of seedless white grapes during microwave vacuum drying. The Page model, was therefore found suitable to describe the microwave vacuum drying of seedless white grapes within the experimental range. It was observed that the drying rate increased with the increase in the microwave power density. The Page model was found to be the optimum model to predict the drying characteristics of carrot slices (Sutar \& Prasad, 2007) and garlic (İlter et al., 2018) under different process conditions.

From the abovementioned experimental results, the moisture content and water loss variation of seedless white grapes during microwave vacuum drying could be predicted relatively precisely, and the online monitoring of the moisture content of seedless white grapes during drying could be achieved. The abovementioned results also provided a basis for the optimization and control of the microwave vacuum drying process of seedless white grapes. A structural analyzer was also used to measure the mechanical properties of dried fruits of seedless white grapes and simulate the key parameters to obtain their drying time. However, due to problems pertaining to the microwave field and the uneven thickness of the seedless white grape materials, it is expected that microwave vacuum drying will lead to over-concentrated

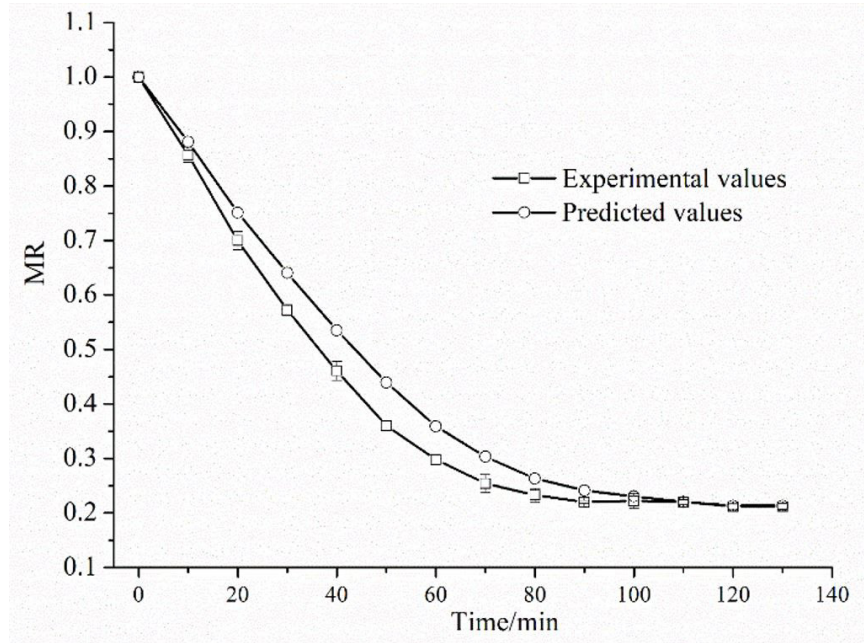

Figure 5. Comparison of the experimental and model-predicted data under identical microwave vacuum drying conditions.

energy and thus local burning. Such problems can affect product quality, and remain to be studied.

Additionally, microwave vacuum processing is more time-efficient as compared to the traditional sheltered drying, which typically occurs between August and September every year. Due to hot weather and dry air, the drying time is approximately a month (Fang et al., 2010), while the microwave vacuum drying only takes approximately $90 \mathrm{~min}$, which dramatically shortens the processing time. The microwave vacuum-dried grape products 
were always golden or brown in color, different from the dark green color of the traditionally shelter-dried seedless white grapes. The color difference was mainly due to the degradation of chlorophyll into lutein and the simultaneous fast moisture loss. The results are consistent with those reported by Clary et al. (2007) that the riboflavin increased during raisin production.

So far, it has been a challenging problem to find the optimum technique to process and preserve grapes. Several studies have been conducted to optimize the drying and pretreatment methods of this fruit (Bai et al., 2013; Guine et al., 2015; Olivati et al., 2019). However, the studies had to focus on quality characteristics in order to produce high-quality raisins and win recognition from customers. The characteristics of grape quality such as color, texture, vitamins, phytochemicals, odor, and microbial stability are all critical (Wang et al., 2015). These quality characteristics can vary during the drying process and directly determine the customers' perception and selection of grape products (Williamson \& Carughi, 2010). Overall, using microwave vacuum drying to process seedless white grapes can control the color, sanitary conditions, shape, and fullness of the grape products, ultimately improving the product quality.

\section{Conclusions}

The microwave drying of seedless white grapes mainly appeared in the deceleration stage. Both the effective moisture diffusivity and the drying rate increased with the increase in the microwave power and decrease in the load weight. The effective moisture diffusivity was also relevant to moisture content and increased with the decrease in the moisture content, under all drying conditions. Liner regression analyses were conducted. The results indicated that the microwave vacuum drying of seedless white grapes followed the Page model. The relationships of moisture content to microwave power, vacuum degree and load weight were all fitted well. The Page model P-value was less than 0.0001 , indicating significant fitting. It was demonstrated that the model predicted data fit well with the experimental data. The Page model can therefore be used to describe the microwave vacuum drying of seedless white grapes.

\section{Acknowledgements}

This work was supported by Key Laboratory of Agro-Products Processing, Ministry of Agriculture and Rural Affairs, P. R. China [grant numbers 009] and National Natural Science Foundation of China [grant numbers 31460438].

\section{References}

Azimi-Nejadian, H., \& Hoseini, S. S. (2019). Study the effect of microwave power and slices thickness on drying characteristics of potato. Heat and Mass Transfer, 55(10), 2921-2930. http://dx.doi.org/10.1007/ s00231-019-02633-x.

Bai, J.-W., Sun, D.-W., Xiao, H.-W., Mujumdar, A. S., \& Gao, Z.-J. (2013). Novel high-humidity hot air impingement blanching (HHAIB) pretreatment enhances drying kinetics and color attributes of seedless grapes. Innovative Food Science \& Emerging Technologies, 20, 230-237. http://dx.doi.org/10.1016/j.ifset.2013.08.011.
Balzarini, M. F., Reinheimer, M. A., Ciappini, M. C., \& Scenna, N. J. (2018). Comparative study of hot air and vacuum drying on the drying kinetics and physicochemical properties of chicory roots. Journal of Food Science and Technology, 55(10), 4067-4078. http:// dx.doi.org/10.1007/s13197-018-3333-5. PMid:30228405.

Briki, S., Zitouni, B., Bechaa, B., \& Amiali, M. (2019). Comparison of convective and infrared heating as means of drying pomegranate arils (Punica granatum L.). Heat and Mass Transfer, 55(11), 31893199. http://dx.doi.org/10.1007/s00231-019-02644-8.

Cao, X., Zhang, M., Mujumdar, A. S., \& Zhong, Q. (2019). Evaluation of quality properties and water mobility in vacuum microwave-dried carrot slices using pulse-spouted bed with hot air. Drying Technology, 37(9), 1087-1096. http://dx.doi.org/10.1080/07373937.2018.1484758.

Clary, C. D., Mejia-Meza, E., Wang, S., \& Petrucci, V. E. (2007). Improving grape quality using microwave vacuum drying associated with temperature control. Journal of Food Science, 72(1), E023-28. http:// dx.doi.org/10.1111/j.1750-3841.2006.00234.x. PMid:17995881.

Clary, C. D., Wang, S. J., \& Petrucci, V. E. (2005). Fixed and incremental levels of microwave power application on drying grapes under vacuum. Journal of Food Science, 70(5), 344-349. http://dx.doi. org/10.1111/j.1365-2621.2005.tb09975.x.

Cuevas, M., Martínez-Cartas, M. L., Pérez-Villarejo, L., Hernández, L., García-Martín, J. F., \& Sánchez, S. (2019). Drying kinetics and effective water diffusivities in olive stone and olive-tree pruning. Renewable Energy, 132, 911-920. http://dx.doi.org/10.1016/j. renene.2018.08.053.

Curi, P. N., Salgado, D. L., Mendonça, K., Pio, R., Ferreira, J. L. G., \& Souza, V. R. (2019). Influence of microwave processing on the bioactive compounds, antioxidant activity and sensory acceptance of blackberry jelly. Food Science and Technology (Campinas), 39(Suppl. 2), 386-391. http://dx.doi.org/10.1590/fst.18618.

Dak, M., \& Pareek, N. (2014). Effective moisture diffusivity of pomegranate arils under going microwave-vacuum drying. Journal of Food Engineering, 122, 117-121. http://dx.doi.org/10.1016/j. jfoodeng.2013.08.040.

Dev, S. R. S., Padmini, T., Adedeji, A., Gariépy, Y., \& Raghavan, G. S. V. (2008). A Comparative Study on the Effect of Chemical, Microwave, and Pulsed Electric Pretreatments on Convective Drying and Quality of Raisins. Drying Technology, 26(10), 1238-1243. http://dx.doi. org/10.1080/07373930802307167.

Dutta, A., Subramanian, A. S., Chakraborty, R., \& Erdogdu, F. (2020). Numerical modeling of water uptake in white rice (Oryza sativa L.) using variable diffusivity approach. Biosystems Engineering, 191, 116-128. http://dx.doi.org/10.1016/j.biosystemseng.2020.01.011.

Eminoglu, M. B., Yegul, U., \& Sacilik, K. (2019). Drying Characteristics of Blackberry Fruits in a Convective Hot-air Dryer. HortScience, 54(9), 1546-1550. http://dx.doi.org/10.21273/HORTSCI14201-19.

Erbay, Z., \& Icier, F. (2010). A Review of Thin Layer Drying of Foods: Theory, Modeling, and Experimental Results. Critical Reviews in Food Science and Nutrition, 50(5), 441-464. http://dx.doi. org/10.1080/10408390802437063. PMid:20373189.

Fang, Y. L., Zhang, A., Wang, H., Li, H., Zhang, Z. W., Chen, S. X., \& Luan, L. Y. (2010). Health risk assessment of trace elements in Chinese raisins produced in Xinjiang province. Food Control, 21(5), 732-739. http://dx.doi.org/10.1016/j.foodcont.2009.10.018.

Giri, S., \& Prasad, S. (2007). Drying kinetics and rehydration characteristics of microwawe-vacum and convective hot-air dried mushrooms. Journal of Food Engineering, 78(2), 512-521. http:// dx.doi.org/10.1016/j.jfoodeng.2005.10.021. 
Guine, R. P. F., Almeida, I. C., Correia, A. C., \& Goncalves, F. J. (2015). Evaluation of the physical, chemical and sensory properties of raisins produced from grapes of the cultivar Crimson. Journal of Food Measurement and Characterization, 9(3), 337-346. http://dx.doi. org/10.1007/s11694-015-9241-8.

Horuz, E., Bozkurt, H., Karatas, H., \& Maskan, M. (2020). Microwaveconventional drying characteristics of red pepper: modeling, temperature profile, diffusivity and activation energy. Journal of Agricultural Science and Technology, 22(2), 425-437.

İlter, I., Akyıl, S., Devseren, E., Okut, D., Koç, M., \& Kaymak Ertekin, F. (2018). Microwave and hot air drying of garlic puree: drying kinetics and quality characteristics. Heat and Mass Transfer, 54(7), 2101-2112. http://dx.doi.org/10.1007/s00231-018-2294-6.

Islam, M., Zhang, M., \& Fan, D. (2019). Ultrasonically enhanced low-temperature microwave-assisted vacuum frying of edamame: Effects on dehydration kinetics and improved quality attributes. Drying Technology, 37(16), 2087-2104. http://dx.doi.org/10.1080/ 07373937.2018.1558234.

Izli, N., \& Polat, A. (2019). Effect of convective and microwave methods on drying characteristics, color, rehydration and microstructure properties of ginger. Food Science and Technology (Campinas), 39(3), 652-659. http://dx.doi.org/10.1590/fst.04518.

Jiang, N., Lagnika, C., Liu, C., Li, D., Yu, Z., Wang, L., Zhang, Z., Liu, C., Xiao, Y., \& Zhang, M. (2020). Dielectric properties of thermosonically treated Agaricus bisporus slices during microwave vacuum drying and correlation with the water state. Drying Technology, 38(4), 448459. http://dx.doi.org/10.1080/07373937.2019.1580717.

Karathanos, V., Villalobos, G., \& Saravacos, G. D. (1990). Comparison of Two Methods of Estimation of the Effective Moisture Diffusivity from Drying Data. Journal of Food Science, 55(1), 218-223. http:// dx.doi.org/10.1111/j.1365-2621.1990.tb06056.x.

Khamtree, S., Ratanawilai, T., \& Nuntadusit, C. (2019). An approach for indirect monitoring of moisture content in rubberwood (Hevea brasiliensis) during hot air drying. Drying Technology, 37(16), 21162125. http://dx.doi.org/10.1080/07373937.2018.1563901.

Khiari, R., Zemni, H., \& Mihoubi, D. (2019). Raisin processing: physicochemical, nutritional and microbiological quality characteristics as affected by drying process. Food Reviews International, 35(3), 246-298. http://dx.doi.org/10.1080/87559129.2018.1517264.

Li, Y., Chen, J., Lai, P., Tang, B., \& Wu, L. (2020). Influence of drying methods on the physicochemical properties and nutritional composition of instant Tremella fuciformis. Food Science and Technology (Campinas), 40(3), 741-748. http://dx.doi.org/10.1590/fst.20519.

McMinn, W. A. M., Khraisheh, M., \& Magee, T. R. A. (2003). Modelling the mass transfer during convective, microwave and combined microwave-convective drying of solid slabs and cylinders. Food Research International, 36(9-10), 977-983. http://dx.doi.org/10.1016/ S0963-9969(03)00118-2.

Meili, L., Perazzini, H., Ferreira, M. C., \& Freire, J. T. (2020). Analyzing the universality of the dimensionless vibrating number based on the effective moisture diffusivity and its impact on specific energy consumption. Heat and Mass Transfer, 56(5), 1659-1672. http:// dx.doi.org/10.1007/s00231-019-02787-8.

Nowacka, M., Wiktor, A., Anuszewska, A., Dadan, M., Rybak, K., \& Witrowa-Rajchert, D. (2019). The application of unconventional technologies as pulsed electric field, ultrasound and microwavevacuum drying in the production of dried cranberry snacks. Ultrasonics Sonochemistry, 56, 1-13. http://dx.doi.org/10.1016/j. ultsonch.2019.03.023. PMid:31101243.

Olivati, C., de Oliveira Nishiyama, Y. P., de Souza, R. T., Janzantti, N. S., Mauro, M. A., Gomes, E., Hermosín-Gutiérrez, I., da Silva,
R., \& Lago-Vanzela, E. S. (2019). Effect of the pre-treatment and the drying process on the phenolic composition of raisins produced with a seedless Brazilian grape cultivar. Food Research International, 116, 190-199. http://dx.doi.org/10.1016/j.foodres.2018.08.012. PMid:30716936.

Ouaabou, R., Nabil, B., Ouhammou, M., Idlimam, A., Lamharrar, A., Ennahli, S., Hanine, H., \& Mahrouz, M. (2020). Impact of solar drying process on drying kinetics, and on bioactive profile of Moroccan sweet cherry. Renewable Energy, 151, 908-918. http:// dx.doi.org/10.1016/j.renene.2019.11.078.

Ozcan-Sinir, G., Ozkan-Karabacak, A., Tamer, C. E., \& Copur, O. U. (2019). The effect of hot air, vacuum and microwave drying on drying characteristics, rehydration capacity, color, total phenolic content and antioxidant capacity of Kumquat (Citrus japonica). Food Science and Technology (Campinas), 39(2), 475-484. http:// dx.doi.org/10.1590/fst.34417.

Peña-Gonzalez, E., Alarcon-Rojo, A. D., Garcia-Galicia, I., CarrilloLopez, L., \& Huerta-Jimenez, M. (2019). Ultrasound as a potential process to tenderize beef: sensory and technological parameters. Ultrasonics Sonochemistry, 53, 134-141. http://dx.doi.org/10.1016/j. ultsonch.2018.12.045. PMid:30639205.

Rodriguez, A., Bruno, E., Paola, C., Campanone, L., \& Mascheroni, R. H. (2019). Experimental study of dehydration processes of raspberries (Rubus Idaeus) with microwave and solar drying. Food Science and Technology (Campinas), 39(2), 336-343. http://dx.doi. org/10.1590/fst.29117.

Shabbir, M. A., Ahmed, H., Maan, A., Salara, A., Afraz, M., Iqbal, M., \& Aadil, R. (2019). Effect of non-thermal processing techniques on pathogenic and spoilage microorganisms of milk and milk products. International Journal of Dairy Technology, 72(4), 481-495. http://dx.doi.org/10.1590/fst.05820.

Sharma, G. P., \& Prasad, S. (2001). Drying of garlic (Allium sativum) cloves by microwave-hot air combination. Journal of Food Engineering, 50(2), 99-105. http://dx.doi.org/10.1016/S0260-8774(00)00200-4.

Sharma, G. P., \& Prasad, S. (2004). Effective moisture diffusivity of garlic cloves undergoing microwave-convective drying. Journal of Food Engineering, 65(4), 609-617. http://dx.doi.org/10.1016/j. jfoodeng.2004.02.027.

Song, C., Ma, X., Li, Z., Wu, T., Raghavan, G. S. V., \& Chen, H. (2020). Mass transfer during osmotic dehydrationand its effect on anthocyanin retention of microwave vacuum-dried blackberries. Journal of the Science of Food and Agriculture, 100(1), 102-109. http://dx.doi. org/10.1002/jsfa.9999. PMid:31436308.

Sutar, P., \& Prasad, S. (2007). Modeling Microwave Vacuum Drying Kinetics and Moisture Diffusivity of Carrot Slices. Drying Technology, 25(10), 1695-1702. http://dx.doi. org/10.1080/07373930701590947.

Wang, D., Cai, J., Zhu, B.-Q., Wu, G.-F., Duan, C.-Q., Chen, G., \& Shi, Y. (2015). Study of free and glycosidically bound volatile compounds in air-dried raisins from three seedless grape varieties using HS-SPME with GC-MS. Food Chemistry, 177, 346-353. http://dx.doi.org/10.1016/j.foodchem.2015.01.018. PMid:25660896.

Wang, D., Duan, C.-Q., Shi, Y., Zhu, B.-Q., Javed, H. U., \& Wang, J. (2017). Free and glycosidically bound volatile compounds in sundried raisins made from different fragrance intensities grape varieties using a validated HS-SPME with GC-MS method. Food Chemistry, 228, 125-135. http://dx.doi.org/10.1016/j.foodchem.2017.01.153. PMid:28317704.

Wang, Z., Sun, J., Chen, F., Liao, X., \& Hu, X. (2007). Mathematical modeling on thin layer microwave drying of apple pomace with 
and without hot-air pre drying. Journal of Food Engineering, 80(2), 536-544. http://dx.doi.org/10.1016/j.jfoodeng.2006.06.019.

Williamson, G., \& Carughi, A. (2010). Polyphenol content and health benefits of raisins. Nutrition Research (New York, N.Y.), 30(8), 511-519. http://dx.doi.org/10.1016/j.nutres.2010.07.005. PMid:20851304.

Yang, F., Zhang, M., \& Liu, Y. (2019). Effect of post-treatment microwave vacuum drying on the quality of 3D-printed mango juice gel. Drying Technology, 37(14), 1757-1765. http://dx.doi.org/10.1080/07373937.2018.1536884.

Zhao, Y., Wang, W., Xie, J., Zheng, B., Miao, S., Lo, Y. M., Zheng, Y., Zhuang, W., \& Tian, Y. (2017). Microwave vacuum drying of lotus seeds: Effect of a single-stage tempering treatment on drying characteristics, moisture distribution, and product quality. Drying Technology, 35(13), 1561-1570. http://dx.doi.org/10.1080/07373937.2016.1261890.
Zhao, Y., Zheng, Y., Li, Z., Jiang, Y., Zhuang, W., Zheng, B., \& Tian, Y. (2020). Effects of ultrasonic pretreatments on thermodynamic properties, water state, color kinetics, and free amino acid composition in microwave vacuum dried lotus seeds. Drying Technology, 38(4), 534-544. http://dx.doi.org/10.1080/07373937.2019.1587618.

Zhou, X., Xu, R., Zhang, B., Pei, S., Liu, Q., Ramaswamy, H. S., \& Wang, S. (2018). Radio frequency-vacuum drying of kiwifruits: kinetics, uniformity, and product quality. Food and Bioprocess Technology, 11(11), 2094-2109. http://dx.doi. org/10.1007/s11947-018-2169-3.

Zielinska, M., Markowski, M., \& Zielinska, D. (2019). The effect of freezing on the hot air and microwave vacuum drying kinetics and texture of whole cranberries. Drying Technology, 37(13), 1714-1730. http://dx.doi.org/10.1080/07373937.2018.1543317. 